\title{
MAPEAMENTO DE ÁREAS DE PRESERVAÇÃO PERMANENTES E IDENTIFICAÇÃO DOS CONFLITOS LEGAIS DE USO DA TERRA NA BACIA HIDROGRÁFICA DO RIBEIRÃO SÃO BARTOLOMEU - MG ${ }^{1}$
}

\author{
Vicente Paulo Soares², Adelson de Azevedo Moreira ${ }^{3}$, Carlos Antonio Alvares Soares Ribeiro², José \\ Marinaldo Gleriani² e Joel Gripp Junior²
}

\begin{abstract}
RESUMO - Este trabalho teve como objetivo delimitar, de maneira automática, as áreas de preservação permanentes e identificar as ocorrências de conflitos legais de uso da terra na bacia do ribeirão São Bartolomeu, situada no município de Viçosa, Minas Gerais. Aplicando-se a técnica clássica de fotointerpretação visual em tela a uma ortoimagem do satélite Ikonos II, foi possível mapear 9 classes de uso e cobertura da terra. O mapeamento automático das áreas de preservação permanentes, com base no Código Florestal brasileiro e respectivas Resoluções do CONAMA, resultou na identificação de 1.530,67 ha de áreas protegidas, distribuídas nas seguintes categorias: ao longo dos divisores d'água (1.037,32 ha), encostas com declividades superiores a 45 graus (5,51 ha), nascentes e suas respectivas áreas de contribuição (436,06 ha), zonas ripárias (325,96 ha) e no topo de morros (27,96 ha). Essas áreas especialmente protegidas correspondem a 54,15 \% da área total da bacia estudada, que é de 2.826,83 ha. Identificaram-se 905,14 ha (59,70 \%) de APPs ilegalmente utilizadas em empreendimentos agropecuários, sendo as classes de pastagem com 40,06\% (613,12 ha) e de cafezal com 7,12 \% (109,02 ha) as principais ocorrências.

Palavras-chave: geoprocessamento, Áreas de Preservação Permanentes e Conflitos de uso da terra.
\end{abstract}

\section{AUTOMATIC MAPPING OF PERMANENT PRESERVATION AREAS AND LAND USE CONFLICTS IN SÃO BARTOLOMEU WATERSHED, STATE OF MINAS GERIAS - BRAZIL}

\begin{abstract}
The objective of this study was to map, automatically, the permanent preservation areas and to identify land use conflicts in São Bartolomeu watershed, State of Minas Gerais - Brazil. Using an Ikonos II orthoimage and geoprocessing resources, it was possible to map nine land use land cover classes through a visual interpretation. Automatic mapping of the permanent preservation areas based on the Brazilian forest code and the respective acts of CONAMA resulted in the identification of 1,530.67 protected areas, distributed in the following categories: along ridgelines (1,037.32 ha), steep slopes greater than 45 degrees (5.51 ha), spring-waters and their contribution areas (436.06 ha), riparian zones (325.96 ha) and on upper third of hilltops (27.96 ha). This areas specially protected corresponded to $54.15 \%$ of the total basin, which is 2,826.83 ha. It was identified $905.14 \mathrm{ha}$ (59.70 \%) of protected areas being illegally in agricultural business, with pasture with 40.06\% (613.12 ha) and coffee with $7.12 \%$ (109.02 ha), the predominant classes.
\end{abstract}

Keywords: Geoprocessing, Permanent preservation areas and Land use conflicts.

\section{INTRODUÇÃO}

O conceito de Área de Preservação Permanente (APP), definido no Código Florestal de 1965, surge do reconhecimento, pela sociedade, em geral, e pelos proprietários rurais, em particular, da importância de se manter a vegetação de determinadas áreas de uma bacia hidrográfica. Os benefícios ambientais decorrentes se estendem às comunidades vizinhas e, principalmente, àquelas situadas à jusante (SKORUPA, 2003).

No meio rural, as APPs assumem importância estratégica no desenvolvimento sustentável, sendo possível apontar uma série de benefícios ambientais

\footnotetext{
${ }^{1}$ Recebido em 15.12.2009 e aceito para publicação em 14.04.2011.

${ }^{2}$ Departamento de Engenharia Florestal, Universidade Federal de Viçosa, UFV, Brasil. E-mail: <vicente@ufv.br>, <cribeiro@ufv.br> e<gleriani@gmail.com>.

${ }^{3}$ Instituto Federal de Educação, Ciência e Tecnologia do Espírito Santo, IFES, Brasil.
} 
decorrentes da manutenção dessas áreas. Citam-se, como exemplos, as áreas marginais aos corpos d'água (rios, córregos, lagos, reservatórios) e nascentes; topos de morros e montanhas, encostas acentuadas, restingas e mangues, dentre outros.

Apesar de o Brasil possuir uma legislação ambiental rigorosa e ampla, os órgãos responsáveis não têm se mostrado ágeis no cumprimento de suas obrigações (CRESTANA et al., 1993). A ausência de procedimentos uniformizados e da infraestrutura necessária para se apurar com o devido rigor as agressões ao meio ambiente são frequentemente apontadas como os principais desafios das agências governamentais. Segundo Nascimento et al. (2005), existem metodologias possíveis de serem implementadas por meio do geoprocessamento que tornam-se alternativas viáveis para se aumentar a eficiência dos órgãos de fiscalização no combate ao descumprimento do nosso Código Florestal. Destaca-se, nesse cenário, a importância de se prover os agentes fiscalizadores com mapas acurados, indicando os limites das áreas de preservação permanente.

O uso de abordagens automatizadas adquire maior importância à medida que o problema a ser analisado apresenta-se em grandes dimensões, complexidade e com custos para operacionalização em campo bastante elevados (PESSOAet al., 1997). Tais situações constituem grande desafio, pois os critérios de delimitação de APPs, com base na topografia, exigem o envolvimento de pessoal especializado e de informações detalhadas da unidade espacial em análise.

Vários trabalhos sobre mapeamento e quantificação das áreas de preservação permanentes e dos conflitos de uso terra, tendo como referência legal o Código florestal e a Resolução nº 303, do CONAMA têm sido desenvolvidos nos últimos anos (SOARES et al., 2002; RIBEIRO et al., 2005; NASCIMENTO et al., 2005; OLIVEIRA, 2005; SERIGATO, 2006; GRIPP JUNIOR, 2009).

Nesse contexto, o presente trabalho teve como objetivos principais delimitar, de forma automática, as áreas de preservação permanentes e identificar e quantificar a ocorrência de conflitos de uso da terra na bacia do ribeirão São Bartolomeu, município de Viçosa, estado de Minas Gerais, com base na interpretação visual em tela utilizando-se uma ortoimagem do satélite Ikonos II.

Revista Árvore, Viçosa-MG, v.35, n.3, p.555-563, 2011

\section{MATERIAL E MÉTODOS}

\subsection{Localização e característica da área de estudo}

A área de estudo situa-se no município de Viçosa, Zona da Mata Mineira, estando compreendida entre as coordenadas geográficas $20^{\circ} 44^{\prime}$ e $20^{\circ} 51^{\prime}$ de latitude Sul e $42^{\circ} 50^{\prime}$ e $42^{\circ} 55^{\prime}$ de longitude Oeste. Esta área de 2.826,83 ha compreende parte da bacia do ribeirão São Bartolomeu, ilustrada na Figura 1.

A região caracteriza-se por um relevo fortemente ondulado, apresentando porções reduzidas de área plana. Apresenta uma altitude média de $649 \mathrm{~m}$, encontrando-se altitudes superiores a $800 \mathrm{~m}$ nos topos dos muitos morros do município (IGA, 1982). Os fundos de seus vales correspondem ao leito maior, periodicamente inundável, seguido de terraços

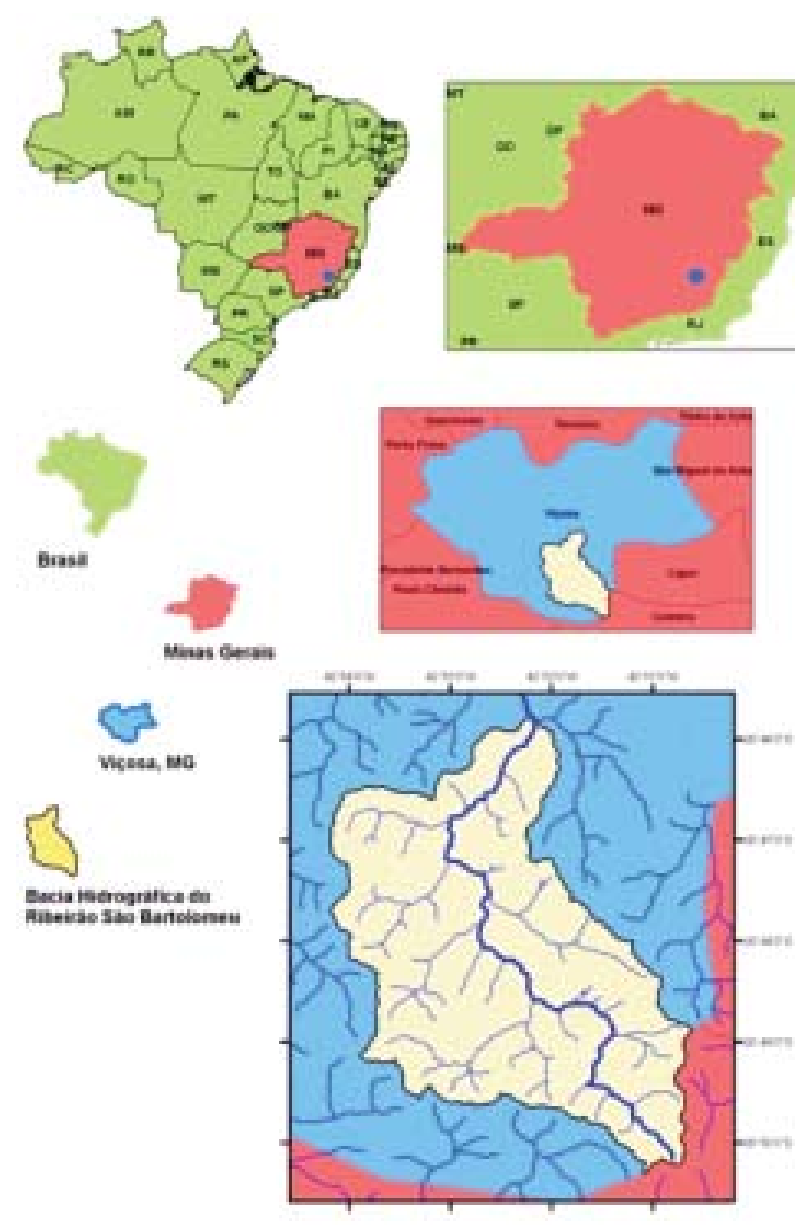

Figura 1 - Localização da área de estudo. Figure 1 - Study area location. 
assimétricos, preferidos para a agricultura e habitações. As vertentes desenvolvem-se seguindo uma linha côncava-convexa-topo e parte íngreme (REZENDE, 1971), com escassos remanescentes florestais nativos, caracterizadas por minifúndios com mão-de-obra essencialmente familiar, onde praticam-se a agricultura e a pecuária de subsistência.

\subsection{Materiais e Aplicativos Utilizados}

Para a consecução desse trabalho utilizaram-se uma ortoimagem do satélite Ikonos II, fusionada colorida com resolução espacial de $1 \mathrm{~m}$; um modelo digital de elevação com padrão de exatidão cartográfica (PEC) classe A para a escala 1:10.000 (SANTOS, 2008), com curvas de nível com equidistância vertical de $5 \mathrm{~m}$; cartas topográficas do IBGE na escala 1/50.000, formato digital e os aplicativos ArcGis 9.3 e Erdas Imagine 9.2.

\subsection{Procedimentos Metodológicos}

\subsubsection{Desenvolvimento do Modelo Digital de Elevação Hidrograficamente Condicionado (MDEHC)}

A geração do MDEHC usa a malha hidrográfica durante o processo de interpolação dos dados de altimetria, para melhorar a definição do relevo ao longo das calhas dos rios. Para tanto, há que se assegurar a conectividade de todos os arcos da hidrografia e a sua correta orientação no sentido do escoamento. A criação do MDEHC foi realizada utilizando o software Anudem versão 5.2, estipulando o valor de $1 \mathrm{~m}$ para a sua resolução geométrica. Em seguida, efetuou-se o refinamento do modelo resultante, segundo a metodologia de Ribeiro et al. (2005). A delimitação da área de drenagem da bacia hidrográfica do ribeirão São Bartolomeu foi feita com o comando watershed do módulo Spatial Analyst do ArcGis, que requer como dados de entrada a grade de direções de escoamento e o ponto associado à foz da bacia. O limite da bacia, assim obtido, foi então utilizado para recortar os dados originais.

\subsubsection{Delimitação das Áreas de Preservação Permanente (APPs) com base na Resolução no 303 CONAMA}

Foi adotada a metodologia usada por Ribeiro et al. (2002, 2005) para delimitação automática das áreas de preservação permanente, implementada tomando por base, o modelo digital de elevação hidrograficamente condicionado. Seguindo-se fielmente as especificações constantes dos art. 2ำ e 3을 da Resolução nº 303/2002 do CONAMA, foram delimitadas as categorias de APPs situadas no terço superior dos morros (APP-1), nas encostas com declividades superiores a $45^{\circ}$ (APP-2), nas nascentes e suas respectivas áreas de contribuição (APP-3), nas zonas ripárias (APP-4) e nos terços superiores das sub-bacias (APP-5).

Para a delimitação das APPs ao redor das nascentes e nas zonas ripárias utilizaram-se as bases de dados correspondentes ao MDEHC e à rede hidrográfica orientada no sentido da foz. Os pontos relacionados às nascentes foram extraídos da hidrografia vetorial. Considerando-se que todos os cursos d'água possuiam larguras inferiores a 10m na região analisada, a categoria APP-4 foi delimitada estabelecendo-se faixas de $30 \mathrm{~m}$ para ambas as margens. A delimitação da categoria APP-3 deu-se em três etapas: primeiramente geraram-se círculos com raio de $50 \mathrm{~m}$, tendo por origem o ponto associado a cada nascente; em seguida, com base na direção de escoamento, identificou-se a bacia de contribuição de cada nascente; finalmente, esses dois conjuntos foram sobrepostos, resultando nas áreas de proteção das nascentes.

Para a delimitação das áreas de preservação permanente em topos de morro, inverteu-se a direção de escoamento do MDEHC por meio da reclassificação dos seus valores; em seguida, eliminaram-se as células associadas à hidrografia e aos divisores d’água. Esse procedimento objetivou garantir que nenhum topo de morro ou montanha estivesse associado a tais feições. Usando a direção de escoamento invertida, os topos de morros foram então identificados como depressões, aplicando-se o comando sink da extensão Spatial Analyst do ArcGIS. A seguir, foram identificadas as bases dos morros, que corresponderam à área de contribuição drenada por sua depressão. Determinaram-se, então, as altitudes da base e do topo de cada morro por meio das identificações, respectivamente, do menor e maior valor de altitude das células do MDEHC que representam o morro. Com isso, obteve-se a altura do morro pela diferença de altitude do topo do morro e altitude da sua base. Finalizando, foram selecionados os morros com altura entre 50 e 300 m e com declividade superior a 30\% na linha mais íngreme. Para identificar as áreas de preservação permanente associadas aos topos dos morros, calculou-se a relação entre altura do topo do morro em relação à base para cada célula do MDEHC. Esse procedimento possibilitou identificar todas as células que possuíam relação igual ou superior a 2/3, correspondendo à APP-1.

Revista Árvore, Viçosa-MG, v.35, n.3, p.555-563, 2011 
Para a delimitação das áreas de preservação permanentes ao longo dos divisores d’água, no terço superior das sub-bacias, calculou-se, para cada célula do MDEHC, a relação entre a sua altura e a altura do topo em relação à base da menor elevação ao longo da linha de cumeada, para cada trecho de $1 \mathrm{~km}$. Em seguida, identificaram-se as células que apresentavam relação igual ou superior a $2 / 3$.

Para a delimitação das áreas de preservação permanente nas encostas ou elevações com declividade superior a $100 \%$, equivalendo a $45^{\circ}$, aplicou-se o comando slope, disponível na extensão Spatial Analyst do ArcGIS; posteriormente, selecionaram-se somente as células que atendiam a esse critério.

\subsubsection{Mapeamento das classes de cobertura e uso da terra}

Na geração do mapa temático de uso e cobertura da terra foi realizada uma interpretação visual da ortoimagem do satélite Ikonos II, gerando-se 9 classes: pastagem, floresta natural, floresta plantada, agricultura, cafezal, área urbana, benfeitorias, hidrografia e vias de acesso. A descrição de cada uma delas encontra-se na Tabela 1.

\subsubsection{Delimitação das áreas de conflito de uso da terra}

Para identificação e análise dos conflitos de uso da terra efetuou-se a sobreposição dos temas cobertura e uso da terra e áreas de preservação permanente, utilizando-se os recursos disponíveis no módulo ArcMap do ArcGis, encontrando-se, assim, as regiões de interseções. Em seguida, foram obtidas as áreas de uso permissível para cada classe de cobertura e uso da terra.

\section{RESULTADOS}

\subsection{Delimitação e quantificação das áreas de preservação permanente}

Foram delimitadas, automaticamente, todas as categorias de APPs diretamente vinculadas ao elementos definidores de uma bacia hidrográfica: situadas no terço superior dos morros, nas encostas com declividades superior a $45^{\circ}$, nas nascentes e suas respectivas áreas de contribuição, ao longo das zonas ripárias e ao longo dos divisores d’água, no terço superior das sub-bacias. A Figura 2 e a Tabela 2 mostra, respectivamente, a distribuição espacial e a participação quantitativa de todas as categorias de APPs presentes na área de estudo

\subsection{Mapeamento das classes de cobertura e de uso da terra}

A ortoimagem do satélite Ikonos II, obtida em outubro de 2007, e os levantamentos de campo permitiram identificar e mapear 9 classes de uso e ocupação da terra: pastagem, floresta natural, cafezal, agricultura, floresta plantada, área urbana, hidrografia, benfeitorias e vias de acesso. O mapa de cobertura e uso da terra e as informações quantitativas são mostrados, respectivamente, na Figura 3 e Tabela 3.

Tabela 1 - Classes de cobertura e uso da terra Table 1 - Land use / land cover classes

\begin{tabular}{|c|c|c|c|}
\hline & Classes de Uso & $\begin{array}{c}\text { Classe } \\
\text { Temática }\end{array}$ & Descrição do Tema \\
\hline 1 & & Pastagem & Área para pastoreio \\
\hline 2 & & $\begin{array}{l}\text { Floresta } \\
\text { Natural }\end{array}$ & $\begin{array}{l}\text { Área coberta com } \\
\text { vegetação em } \\
\text { diferentes estágios }\end{array}$ \\
\hline 3 & & $\begin{array}{l}\text { Floresta } \\
\text { plantada }\end{array}$ & $\begin{array}{l}\text { Plantio de } \\
\text { eucaliptos ou pinus. }\end{array}$ \\
\hline 4 & & Agricultura & $\begin{array}{l}\text { Culturas anuais } \\
\text { (milho, feijāo, } \\
\text { hortaliças) e pomar. }\end{array}$ \\
\hline 5 & & cafezal & $\begin{array}{l}\text { Cultura perene com } \\
\text { café }\end{array}$ \\
\hline 6 & & $\begin{array}{l}\text { Área } \\
\text { urbana }\end{array}$ & $\begin{array}{l}\text { Casas, ruas, vias, } \\
\text { parte urbanizads }\end{array}$ \\
\hline 7 & & Benfeitorias & $\begin{array}{l}\text { Edificações e } \\
\text { benfeitorias, casa, } \\
\text { terreiro, estradas } \\
\text { internas }\end{array}$ \\
\hline 8 & & Hidrografia & $\begin{array}{l}\text { Lagos e cursos de } \\
\text { água }\end{array}$ \\
\hline 9 & , & $\begin{array}{l}\text { Vias de } \\
\text { acesso }\end{array}$ & $\begin{array}{l}\text { Rodovia Estadual } \\
\text { pavimentada e vias } \\
\text { de acesso ao imóve }\end{array}$ \\
\hline
\end{tabular}




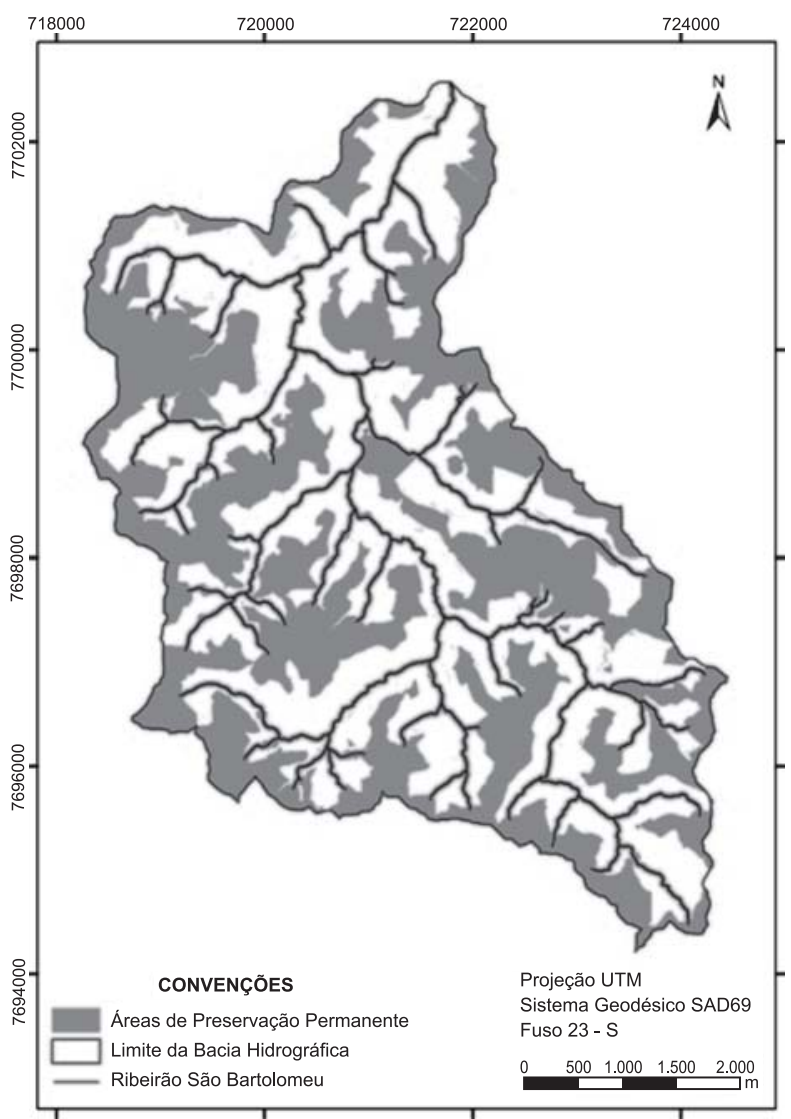

Figura 2 - Mapa com todas as categorias de Áreas de Preservação Permanentes da bacia do ribeirão São Bartolomeu, Minas Gerais.

Figure 2-Map showing the categories of Permanent Preservation Areas in São Bartolomeu watershed, State of Minas Gerais, Brazil.

Tabela 2 - Quantificação das Áreas de Preservação Permanente (APPs) na bacia do ribeirão São Bartolomeu, Minas Gerais.

Table 2 - Quantification of Permanent Preservation Areas in Ribeirão São Bartolomeu watershed, State of Minas Gerais, Brazil.

\begin{tabular}{ccc}
\hline Categorias de APPs & Área (ha) & $\%$ \\
\hline Topos de Morro & 27,96 & 1,83 \\
${\text { Encostas com Declividade superior a } 45^{\circ}}^{\circ}$ & 5,51 & 0,36 \\
Nascentes e suas Áreas de Contribuição & 436,06 & 28,49 \\
Na zona ripária & 325,96 & 21,30 \\
Terço Superior das Sub-bacias & $1.037,32$ & 67,77 \\
\hline Total de APPs & $1.530,67$ & 54,15 \\
\hline Área Total da Bacia & $2.826,83$ & 100 \\
\hline
\end{tabular}

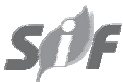

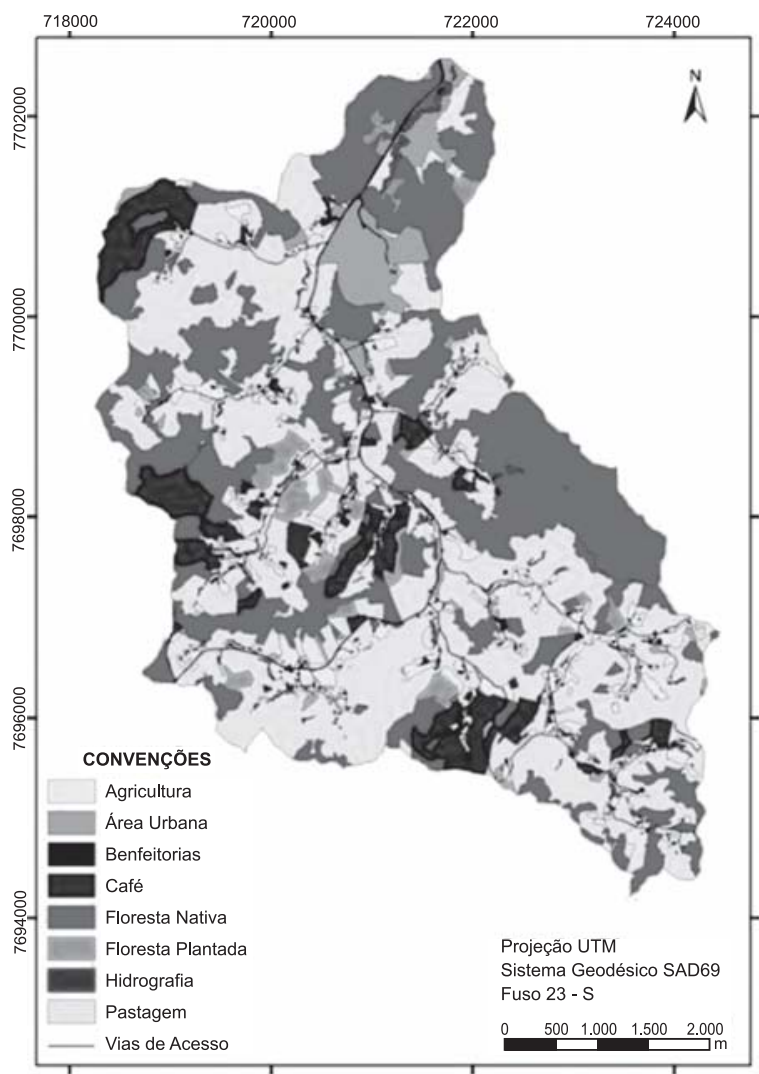

Figura 3 - Mapa das classes de cobertura e uso da terra da bacia do ribeirão São Bartolomeu, município de Viçosa, Minas Gerais.

Figure 3-Land use / land cover classes map in São Bartolomeu watershed, State of Minas Gerais, Brazil.

Tabela 3 - Classes de cobertura e uso da terra na bacia do ribeirão São Bartolomeu, Minas Gerais, com seus respectivos perímetros (m), áreas (ha) e percentagens.

Table 3 - Land use / land cover classes in the ribeirão São Bartolomeu watershed, State of Minas Gerais, Brazil, with their respective perimeters, areas and percentages.

\begin{tabular}{|c|c|c|c|}
\hline \multirow{2}{*}{$\begin{array}{c}\text { Classes de Cobertura } \\
\text { e Uso da Terra }\end{array}$} & \multirow{2}{*}{$\begin{array}{l}\text { Perímetro } \\
\mathrm{m}\end{array}$} & \multicolumn{2}{|c|}{ Área } \\
\hline & & ha & $\begin{array}{c}\text { \% da área } \\
\text { total }\end{array}$ \\
\hline Agricultura & $121.442,403$ & 217,57 & 7,70 \\
\hline Área urbana & $19.759,066$ & 105,71 & 3,74 \\
\hline Benfeitoria & $60.146,610$ & 29,21 & 1,03 \\
\hline Cafezal & $41.321,650$ & 211,84 & 7,49 \\
\hline Floresta nativa & $155.137,074$ & 908,73 & 32,15 \\
\hline Floresta plantada & $28.574,104$ & 90,23 & 3,19 \\
\hline Hidrografia & $40.894,526$ & 30,28 & 1,07 \\
\hline Pastagem & $258.363,427$ & $1.207,05$ & 42,70 \\
\hline \multirow[t]{2}{*}{ Vias de acesso } & $77.113,181$ & 26,21 & 0,93 \\
\hline & Total & $2.826,83$ & $\overline{100,00}$ \\
\hline
\end{tabular}

Revista Árvore, Viçosa-MG, v.35, n.3, p.555-563, 2011 


\subsection{Conflitos de uso da terra}

A Figura 4 mostra o mapa de cobertura e uso da terra nas APPs. Já a Tabela 4 mostra a quantificação da ocorrência de conflito de uso da terra nas APPs, enquanto que a Tabela 5 mostra a quantificação das áreas ocupadas pelas classes de uso da terra em observância à legislação ambiental.

\section{DISCUSSÃO}

A análise quantitativa da Tabela 2 mostra que a menor e a maior participação entre as categorias de APPs corresponderam às encostas com declividades superiores a $45^{\circ}$ e terço superior das sub-bacias, com 5,51 ha $(0,36 \%)$ e $1.037,32$ ha $(67,77 \%)$ respectivamente.
As categorias proteção de nascentes contribuíram com 436,06 ha $(28,49 \%)$ e as zonas repárias, 325,96 ha (21,30\%). Nota-se, ainda, que as APPs ocuparam uma área de 1.530,67 ha de um total de 2.826,83 ha da área de estudo, representando 54,15\% de áreas legalmente protegidas.

Diversos trabalhos realizados na Zona da Mata Mineira sobre mapeamento de Áreas de Preservação Permanentes mostraram resultados similares ao encontrado, a saber: Oliveira (2002), no município de Viçosa - 52,13\%; Oliveira et al. (2008), nos municípios de Alto Jequitibá, Alto Caparaó, Caparaó e Espera Feliz - 48,06\%; e Gripp Junior (2009), nos municípios de Canaã, Araponga e Ervália - 54\%.

Tabela 4 - Quantificação da ocorrência de conflito de uso da terra nas categorias de Áreas de Preservação Permanente, em ha, delimitadas na bacia do ribeirão São Bartolomeu, município de Viçosa, Minas Gerais.

Table 4 - Quantification of land use conflict inside Permanent Preservation Areas (ha) in the Ribeirão São Bartolomeu watershed, State of Minas Gerais, Brazil.

\begin{tabular}{lcccccccc}
\hline $\begin{array}{c}\text { Classes de Cobertura } \\
\text { e Uso da Terra }\end{array}$ & & APP-1 & APP-2 & APP - 3 & APP - 4 & APP - 5 & $\begin{array}{c}\text { Total de } \\
\text { APPs }\end{array}$ & $\begin{array}{c}\% \text { da área } \\
\text { total }\end{array}$ \\
\hline Sistema antrópico & Agricultura & 0,57 & 0,19 & 16,56 & 42,55 & 27,19 & 77,81 & 5,08 \\
& Área Urbana & - & 0,11 & 7,64 & 12,76 & 30,34 & 46,24 & 3,02 \\
Benfeitorias & & 0,05 & 0,00 & 0,54 & 8,54 & 1,72 & 10,20 & 0,67 \\
& Cafezal & 2,44 & 0,27 & 38,55 & 11,22 & 82,70 & 109,02 & 7,12 \\
& Floresta Plantada & 1,18 & 0,22 & 7,69 & 0,63 & 36,25 & 40,85 & 2,67 \\
& Pastagem & 13,23 & 2,57 & 206,08 & 156,52 & 360,92 & 613,12 & 40,06 \\
& Vias de Acesso & - & 0,01 & 1,45 & 5,17 & 2,28 & 7,90 & 0,52 \\
\hline Sistema fitofisionômico & Floresta Nativa & 10,49 & 2,14 & 156,41 & 60,83 & 495,15 & 597,35 & 39,03 \\
& Hidrografia & - & 0,01 & 1,13 & 27,76 & 0,76 & 28,20 & 1,84 \\
& Total & $\mathbf{2 7 , 9 6}$ & $\mathbf{5 , 5 1}$ & $\mathbf{4 3 6 , 0 6}$ & $\mathbf{3 2 5 , 9 6}$ & $\mathbf{1 . 0 3 7 , 3 2}$ & $\mathbf{1 . 5 3 0 , 6 7}$ & $\mathbf{1 0 0 , 0 0}$ \\
\hline
\end{tabular}

Tabela 5 - Quantificação das áreas ocupadas pelas classes de uso da terra em observância à legislação ambiental, na bacia do ribeirão São Bartolomeu, município de Viçosa, Minas Gerais.

Table 5 - Quantification of areas occupied by land use/land cover classes according to environmental laws in the São Bartolomeu watershed, State of Minas Gerais, Brazil.

\begin{tabular}{|c|c|c|c|c|c|}
\hline \multirow[t]{3}{*}{ Classes de Uso da Terra } & \multirow[t]{3}{*}{ Área Total (ha) } & \multicolumn{4}{|c|}{ Ocorrência } \\
\hline & & \multicolumn{2}{|c|}{ Uso Legal } & \multicolumn{2}{|c|}{ Uso Indevido } \\
\hline & & ha & $\%$ & ha & $\%$ \\
\hline Agricultura & 217,57 & 139,76 & 64,24 & 77,81 & 35,76 \\
\hline Area urbana & 105,71 & 59,47 & 56,26 & 46,24 & 43,74 \\
\hline Benfeitoria & 29,21 & 19,01 & 65,09 & 10,20 & 34,91 \\
\hline Cafezal & 211,84 & 102,82 & 48,54 & 109,02 & 51,46 \\
\hline Floresta plantada & 90,23 & 49,39 & 54,73 & 40,85 & 45,27 \\
\hline Pastagem & $1.207,05$ & 593,94 & 49,21 & 613,12 & 50,79 \\
\hline Vias de acesso & 26,21 & 18,31 & 69,86 & 7,90 & 30,14 \\
\hline Floresta nativa & 908,73 & 908,73 & 100,00 & 0,00 & 0,00 \\
\hline Hidrografia & 30,28 & 30,28 & 100,00 & 0,00 & 0,00 \\
\hline Total & $2.826,83$ & $1.893,51$ & & 933,32 & \\
\hline
\end{tabular}

Revista Árvore, Viçosa-MG, v.35, n.3, p.555-563, 2011 
É importante ressaltar que sempre haverá uma sobreposição natural de APPs de diferentes categorias, principalmente entre as categorias proteção de nascentes e terço superior das sub-bacias e entre zonas de proteção ripária e proteção de nascentes. No cômputo total das APPs, as áreas de superposições são contabilizadas uma única vez.

Com relação ao mapeamento da cobertura e uso da terra, observa-se, pela Tabela 3 , que a classe de pastagem, com $1.207,05$ ha $(42,70 \%)$ é a de maior ocorrência na área de estudo, seguida de floresta nativa com 908,73 ha (32,15\%), totalizando 74,85\%. Já as classes de menores ocorrências foram benfeitoria, hidrografia e vias de acesso, com 29,21 ha, 30,28 ha, 16,21 ha, respectivamente. O predomínio da classe de pastagem na área de estudo é um retrato da realidade que ocorre em toda a região da Zona da Mata Mineira.

Com relação à análise de conflitos de usos, as classes de uso da terra mapeadas estão parcialmente situadas nas áreas legalmente protegidas, principalmente aquelas resultantes de ações antrópicas. Observa-se, na Tabela 4, que a classe Pastagem ocupa 613,12 ha (40,06\%) das APPs, sendo grande parte desta localizada no terço superior das sub-bacias (360,92 ha), seguida da classe Cafezal, com 109,02 ha (7,12\%). As classes de benfeitorias e vias de acesso foram as com menores presenças em APPs. Cabe destacar que, dos 90,23 ha de florestas plantadas, 40,85 ha $(45,27 \%)$ estão localizados em áreas de preservação permanente, caracterizando descumprimento da legislação florestal.

A análise da Tabela 5 mostra que aproximadamente metade das áreas ocupadas pelas classes Pastagem e Cafezal situam-se em áreas de preservação permanente, configurando crime ambiental. No geral, todas as classes de uso da terra na área de estudo apresentaram mais de 30\% de suas áreas em APPs, contrariando a legislação ambiental vigente.

A Figura 4 mostra o mapa de cobertura e uso da terra em APPs, com destaque para a classe de pastagem, cuja ocorrência se dá por toda a área de estudo. A existência de 311,38 ha de florestas nativas fora das áreas de preservação permanente reforça a importância estratégica que o mapeamento das APPs representa para o fiel cumprimento do Código Florestal. Conforme conclui Gonçalves(2009), isso indica claramente que o desconhecimento dos limites das áreas protegidas faz com que o agricultor explore áreas que deveriam

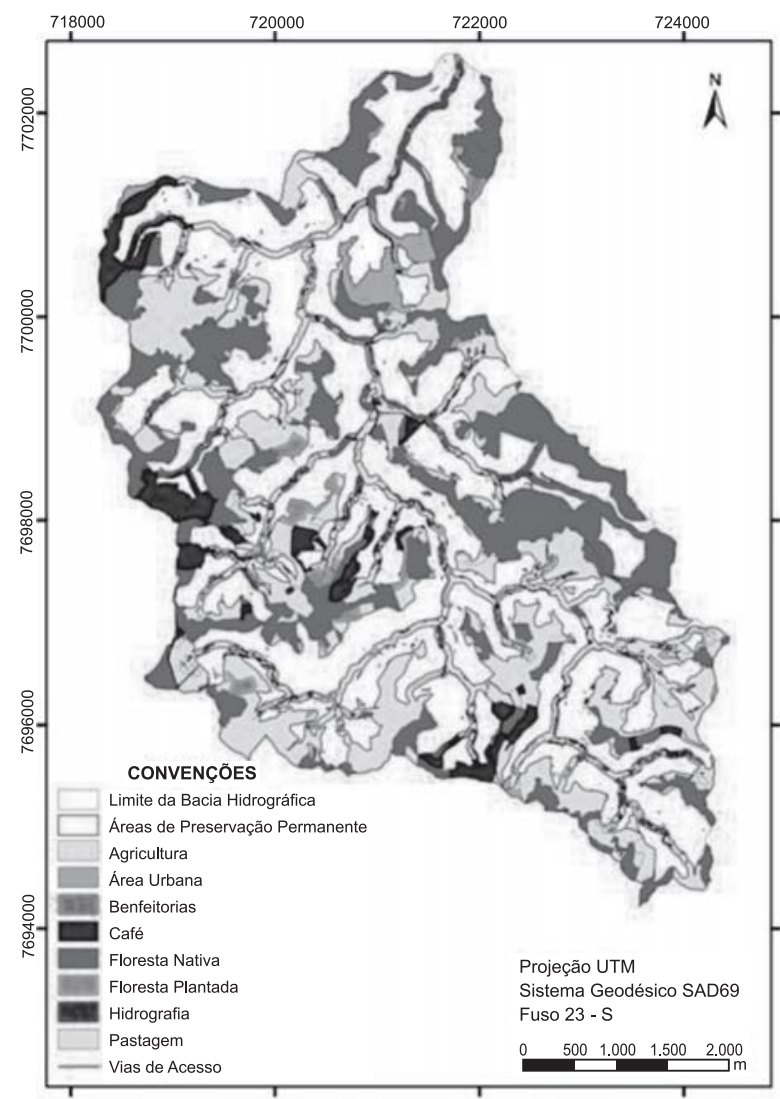

Figura 4 - Mapa de cobertura e uso da terra em áreas de Áreas de Preservação Permanente mapeadas na bacia do ribeirão São Bartolomeu, município de Viçosa, Minas Gerais.

Figure 4-Land use / land cover classes map inside Permanent Preservation Areas in São Bartolomeu watershed, State of Minas Gerais, Brazil.

estar protegidas, enquanto que outras, que poderiam ser legalmente utilizadas para atividades agropecuárias, são mantidas com a cobertura florestal nativa.

Resultado similar em trabalho relacionado a mapeamento de áreas com conflito de uso da terra foi encontrado por Nascimento et al.(2005), na bacia do Rio Alegre, sul do Estado do Espírito Santo. Os autores concluíram que a área de uso indevido correspondeu a 43,80\% da bacia, sendo as classes Cafezal e Pastagem as principais ocorrências em APPs.

\section{CONCLUSÕES}

- A adoção do Sistema de Informações Geográficas permitiu a delimitação automática das áreas de preservação permanente, de forma bastante 
eficiente, produzindo informações acuradas sobre as suas dimensões e distribuição espacial na paisagem.

- A utilização de ortoimagem de alta resolução espacial do satélite Ikonos II permitiu o mapeamento de 9 classes de cobertura e uso da terra, com destaque para a classe Pastagem, ocupando 42,70\% da área total da bacia hidrográfica do ribeirão São Bartolomeu, que é de 2.826,83 ha.

- As categorias de áreas de preservação permanente mapeadas ocuparam uma superfície de 1.536,67 ha, representando 54,15\% da área total da bacia estudada. As categorias de APPs situadas ao longo dos divisores d’água e nas encostas com declividades superiores a $45^{\circ}$ foram as de maior e menor contribuição, enquanto que as categorias de APPs situadas nas nascentes e suas respectivas áreas de contribuição e no terço superior dos morros foram as menos afetadas pelas classes de uso da terra.

- Em se tratando do conflito legal de uso da terra, a área de uso indevido correspondeu a 933,32 ha (33,02\%) sendo que as classes Pastagem, com 613,12 ha (50,79\%), e Cafezal, com 109,02 há (51,46\%,) estão entre as principais ocorrências nas áreas protegidas pelo Código Florestal. Do total de APPs identificadas, 616,91 ha (40,30\%) estão protegidas, encontrando-se cobertas com florestal natural.

- Os resultados demonstram claramente que a ausência de mapas acurados contendo os limites das áreas de preservação permanente dificulta, se não impede, tanto o agricultor de cumprir quanto os órgãos fiscalizadores de fazerem cumprir fielmente o Código Florestal brasileiro.

\section{AGRADECIMENTOS}

A Fundação de Amparo à Pesquisa do Estado de Minas Gerais (FAPEMIG) pelo suporte financeiro.

\section{REFERÊNCIAS}

GONÇALVES, A. B. Delimitação automática das áreas de preservação permanente e identificação dos conflitos de uso da terra na sub-bacia hidrográfica do rio Camapuã/Brumado. 2009. Dissertação (Mestrado em Ciências Florestais) Universidade Federal de Viçosa, Viçosa-MG, 2009.
GRIPP JUNIOR. J. A ortorretificação de Imagens de alta resolução para aplicação em estudo do cadastro técnico rural e mapeamento de áreas de preservação permanente e reservas legais. 2009. 152 f. Tese (Doutorado em Ciência Florestal) - Universidade Federal de Viçosa, Viçosa-MG, 2009.

INSITTUTO DE GEOCIÊNCIAS APLICADAS IGA. Carta de declividade, hidrografia e rodovias de Viçosa. Belo Horizonte-MG: 1982 (Mapa).

NASCIMENTO, M. C. et al. Uso do geoprocessamento na identificação de conflito de uso da terra em áreas de preservação permanente na bacia do rio Alegre, Espírito Santo. Ciência Florestal, v. 15, n. 2, p. 207-220, 2005.

OLIVEIRA, M. J. Uma proposta metodológica para a delimitação automática de áreas de preservação permanente em topos de morro em linhas de cumeada. 2002. Dissertação (Mestrado em Ciências Florestais) - Universidade Federal de Viçosa, Viçosa-MG, 2002.

OLIVEIRA, A. M. S. Impacto econômico da implantação de áreas de preservação permanente na bacia do Rio Alegre, município de Alegre-ES. Dissertação (Mestrado em Ciências Florestais) - Universidade Federal de Viçosa, Viçosa - MG, 2005, 62p.

OLIVEIRA, F. S. Diagnóstico dos

fragmentos florestais e das áreas de preservação permanente no entorno do Parque Nacional do Caparaó, no estado de Minas Gerais. 2006. Dissertação (Mestrado em Ciências Florestais) - Universidade Federal de Viçosa, Viçosa - MG, 2006, 59p.

OLIVEIRA, F. S. et al. Identificação de conflito de uso da terra em Áreas de Preservação Permanente no entorno do parque nacional do Caparão, Estado de Minas Gerais. Revista Árvore, n. 5, v. 32, p. 899-908, 2008.

REZENDE, S. B. Estudo de cronotoposequência em Viçosa - Minas Gerais. 1971. 71 f. Dissertação (Mestrado em Fitotecnia) - Universidade Federal de Viçosa, Viçosa-MG, 1971. 
RIBEIRO, C. A. A. S. et al. Delimitação automática de áreas de preservação permanente em topos de morro e em linhas de cumeada: metodologia e estudo de caso. In: SEMINÁRIO DE ATUALIZAÇÃO EM SENSORIAMENTO REMOTO E SISTEMAS DE INFORMAÇÕES GEOGRÁFICAS APLICADOS À ENGENHARIA FLORESTAL, 5., 2002, Curitiba-PR. Anais... Curitiba-PR: FUPEF, 2002.

RIBEIRO, C. A. A. S. et al. O desafio da delimitação de áreas de preservação permanente. Revista Árvore. n. 2, v. 29, p. 203-212, 2005.

SANTOS, P. A. Avaliação do padrão de exatidão cartográfica em imagens Ikonos e CBERS-2B na bacia do ribeirão São Bartolomeu, em Viçosa-MG. 2008. 41 f. Monografia (Engenharia de Agrimensura) - Universidade Federal de Viçosa, Viçosa-MG, 2008.
SERIGATO, E. M. Delimitação automática das áreas de preservação permanente e identificação dos conflitos de uso da terra na bacia hidrográfica do rio Sepotuba-MT. Tese (Doutorado em Ciência Florestal) - Universidade Federal de Viçosa, Viçosa-MG, 2006.

SKORUPA, L. A. Áreas de preservação permanente e desenvolvimento sustentável. Jaguariúna: Embrapa, 2003. 4p.

SOARES, V. P. et al. Avaliação das áreas de uso indevido da terra em uma micro-bacia no município de Viçosa - MG, através de fotografias aéreas e sistema de informação geográfica. Revista Árvore. v. 26, n. 2, p. 243-251, 2002. 